Meta

Journal des traducteurs

Translators' Journal

\title{
Linguistic Dimensions of Subtitling. Perspectives from Taiwan
}

\section{Sheng-Jie Chen}

Volume 49, numéro 1, avril 2004

Traduction audiovisuelle

Audiovisual Translation

URI : https://id.erudit.org/iderudit/009027ar

DOI : https://doi.org/10.7202/009027ar

Aller au sommaire du numéro

\section{Éditeur(s)}

Les Presses de l'Université de Montréal

ISSN

0026-0452 (imprimé)

1492-1421 (numérique)

Découvrir la revue

Citer cet article

Chen, S.-J. (2004). Linguistic Dimensions of Subtitling. Perspectives from Taiwan. Meta, 49(1), 115-124. https://doi.org/10.7202/009027ar

\section{Résumé de l'article}

On se propose d'aborder la dimension linguistique du sous-titrage en chinois de films et de programmes télévisés en anglais. Les données proviennent de diverses publications, d'entretiens avec deux traducteurs et deux responsables d'agence de traduction, ainsi que de mes propres expériences en tant que traducteur chevronné. En outre, quatre films ont été analysés. Ainsi diverses méthodes ont été utilisées pour approcher notre objet de recherche. Les résultats indiquent que plusieurs facteurs affectent la qualité du sous-titrage notamment le piratage cinématographique, la sous-traitance non contrôlable, des contraintes économiques. Parmi les paramètres linguistiques, on peut noter que, dans le sous-titrage chinois, les jurons sont atténués, des marques de ponctuation et des informations de faible signification sont omises, tandis que des expressions chinoises soutenues peuvent être employées pour leur brièveté, en dépit du registre du texte de départ. 


\title{
Linguistic Dimensions of Subtitling. Perspectives from Taiwan*
}

\author{
SHENG-JIE CHEN \\ National Taiwan University of Science and Technology, Taiwan, ROC \\ shengjie@mail.ntust.edu.tw
}

\begin{abstract}
RÉSUMÉ
On se propose d'aborder la dimension linguistique du sous-titrage en chinois de films et de programmes télévisés en anglais. Les données proviennent de diverses publications, d'entretiens avec deux traducteurs et deux responsables d'agence de traduction, ainsi que de mes propres expériences en tant que traducteur chevronné. En outre, quatre films ont été analysés. Ainsi diverses méthodes ont été utilisées pour approcher notre objet de recherche. Les résultats indiquent que plusieurs facteurs affectent la qualité du sous-titrage - notamment le piratage cinématographique, la sous-traitance non contrôlable, des contraintes économiques. Parmi les paramètres linguistiques, on peut noter que, dans le sous-titrage chinois, les jurons sont atténués, des marques de ponctuation et des informations de faible signification sont omises, tandis que des expressions chinoises soutenues peuvent être employées pour leur brièveté, en dépit du registre du texte de départ.
\end{abstract}

\section{ABSTRACT}

This study investigates the linguistic dimensions of the subtitling of English movies into Chinese. The data derive from literature analysis, interviews with experienced subtitlers and administrators of translation agencies, my self-analysis as an experienced subtitler, and an analysis of four English movies rendered into Chinese subtitles. Grounded research methods are used to analyze the data and complete the report. The results indicate that several factors affect the quality of subtitling, including movie pirating, uncontrollable outsourced projects, economic factors, and linguistic factors. In the Chinese subtitles, swearwords are toned down, some punctuation marks and inessential information are omitted, and despite the source-language register, literary Chinese is used for brevity.

\section{MOTS-CLÉS/KEYWORDS}

linguistic norms, Mandarin Chinese, quality, subtitling, toning down (strategy)

\section{Introduction}

This study investigates the linguistic dimensions and the prescriptive norms of subtitling from English to Chinese in Taiwan, where most of the foreign films that are subtitled in Mandarin Chinese are in English. However, the quality of such subtitles is often poor due to various factors. The data of this study consist of the analysis of existing literature and the subtitles of four movies, interviews with two experienced subtitlers and two administrators of translation agencies, and my self-reflections on my subtitling experience. The data are analyzed based on three major types of coding: open coding, axial coding, and selective coding, as typically used in grounded methods (Strauss \& Corbin, 1990). Our study attempts to answer the following questions: 
What factors affect the quality of subtitling? What are the linguistic dimensions of subtitling? How may the quality of subtitling be enhanced?

This study first introduces the background of the study and factors that may affect subtitling in Taiwan. Second, it reviews the literature on subtitling, focusing on subtitling in Taiwan. Third, it integrates the existing research with interviews, analysis of the subtitles of four movies, and my self-reflections to profile the linguistic dimensions of subtitling through triangulation of the data. In conclusion, it offers suggestions for enhancing subtitling quality in Taiwan.

\section{Background}

\subsection{The need for subtitling}

Mandarin Chinese is the official language of Taiwan. Taiwanese and Hakka are major dialects in addition to the languages of the ten aboriginal tribes. English is the predominant foreign language that is currently taught from grade four of primary school. However, most people use. English in their English classrooms only, so most of them rely on Chinese subtitles when they watch an English movie because very few of them can understand movie English. As a result, all the English movies carry subtitles, partly because there is a need for it and partly because, according to governmental regulations, all the foreign films that are released with original soundtracks require subtitles (Gong gong dien shi fa, 2001). Although movie subtitles, have probably the second largest number of users, next to news translation, among Taiwan's translation consumers, the quality of subtitling is poor. There are several factors that may affect the quality of subtitling.

\subsection{Subtitling quality}

The factors that affect the quality of subtitling may be summarized as follows: Movie pirating, uncontrollable outsourced projects, economic factors, and linguistic factors.

Before the lifting of martial law in 1987, in addition to movies played in theaters and videotapes available in audiotape rental outlets, there were a few underground studios that pirated foreign films. These illegitimate studios imported master copies of American films, hired translators to provide subtitles to the movies, mass-produced them, and then distributed them through underground channels. Copyright law existed at that time but was not strictly enforced. Because the sources of the movies were unreliable, hardly any of the movies thus imported came with a transcript; therefore, subtitlers, who were usually recruited from the students of foreign language departments or moonlighting office workers, relied on watching the movie played on a VCR and listening to the sound track when they subtitled the movie. Sometimes they translated only by listening to an audiotape of the movie soundtrack.

Since the lifting of martial law in Taiwan, the restrictions on media have been loosened, resulting in an inundation of foreign movies throughout the cable channels and movie theaters in Taiwan. Particularly after 1995, in addition to the three television companies, approximately forty cable companies have begun operations in Taiwan (Huang, 2001). Translation quality has improved because legitimate companies run the businesses. Some TV or movie companies even have their own translation 
departments and quality control mechanisms. In addition, the merging of multimedia companies has not only strengthened the companies but also raised the standard of subtitling because they are more organized. Meanwhile, old subtitlers have improved their skills over time. However, the quality is still not quite reliable partly because the new subtitlers are not systematically trained and partly because many movie or TV companies outsource translation projects to individual translators or small subtitling agencies. The quality of such translation assignments is difficult to control.

Movie companies often spend hundreds of thousands, or even millions of dollars, on producing a movie, but they seem reluctant to spend a couple of hundred dollars to get a movie subtitled appropriately. With the exception of a very few famous translators, subtitlers are paid a meager fee for subtitling a movie, and most of them are part-timers. Moreover, subtitlers do not get royalties as book translators do. The subtitlers have to complete their translation projects quickly in order to make ends meet, so they usually do not proofread.

Linguistic factors derive mainly from differences in syntactic structures, the difficulty in adaptation, and untranslatability. First, in many cases, the structures of Chinese and English sentences are different. This discrepancy presents a problem because when the speaker is saying one part of the sentence, the subtitles are showing another part. In addition, it is difficult to adapt - to decide which part to translate and which to omit. Second, there is always something untranslatable, such as accents, different types of English, and special styles of delivery. Finally, there are also other linguistic factors that may affect subtitling.

\section{Literature review}

The literature on subtitling in Taiwan derives mainly from the M.A. theses completed by the students of the Graduate Institute of Translation and Interpretation Studies at $\mathrm{Fu}$ Jen Catholic University in Taiwan, an unpublished translators handbook of the Sun Movie Television Company, Ltd., (see Chiu, et al. 1999) and an unpublished translators handbook (see Yi Zhe Shou Ce, 2001) written by the English Translation Section of Videoland, Inc., a major TV company in Taiwan.

Lee (1988), a prominent experienced subtitler, introduced the following fundamental principles of subtitling: Observe line restraints and word restraints, use simple language, synchronize with the soundtrack, edit the target language for fluency, and chunk the subtitle at phrase units.

Liu (1992) conducted a study on the effects of subtitles on eye fatigue and found that subtitles cause eye fatigue because people who watch subtitled English movies tend to focus on reading the subtitles.

Chen (1996) analyzed the subtitles of twenty-five movies to identify the use of interjections and reached the following conclusions: First, using the same interjections repeatedly in the subtitle should be avoided. Second, Chinese counterparts, or similar Chinese interjections, should be used if they are available; otherwise, Chinese interjections should be created based on Chinese word formation principles. Third, swearwords should be toned down if the movie is for minors or a general audience; however, they should be translated faithfully for an adult audience to show the tone of the movie. 
Chin (1997) posited that for clarity and brevity, the subtitler should follow these translation processes:

- Break the source language message into several thought units,

- Translate these thought units one by one, using common words, phrases, and expressions that are easily comprehensible, and

- Revise the subtitles into fluent Chinese.

In addition, Chin pointed out that for clarity and conciseness, the subtitler should use familiar words, use as few words as possible, and use colloquial and idiomatic expressions. In short, subtitles must be clear and easily comprehensible, without leaving any trace of translation.

Lue (1998), based on her four years' experience serving as a translator and reporter at a major local TV company, concluded that subtitlers should take into account the impact words have in the target culture; should systematically translate foreign scientific (including medical) terms into Chinese terms that are acceptable to Chinese aesthetics and taste, should translate Japanese and Korean names based not on their pronunciation but on their Chinese characters because most people of these countries have names in Chinese characters, should tone down swearwords, and should proofread the final translation for accuracy.

Chiu, et al. (1999) translated a translator's handbook from the Sun Movie Television Company, Ltd., into English. The topics this handbook covers include the characteristics of subtitling, semantic density, brevity, punctuation, wording, synchronization, register, and colloquialism.

Yeh (1999) compared the differences between subtitling and dubbing from communicative perspectives. She indicated that a major difference between subtitling and dubbing is that although both serve the purpose of communication, the essential principle of subtitling is clarity and brevity, whereas that of dubbing is synchronization. Therefore, a subtitler should simplify and shorten the subtitle; on the other hand, the dubber should extend the lines to synchronize with the pictures on the screen or the mouth shapes of the speaker and the narrator.

Yi zhe shou ce (2001) explains the special characteristics of subtitling and provides basic directions on word restrictions, line restrictions, the usage of punctuation marks and numbers, and the translation of inverted sentences.

Huang (2001), an experienced subtitler at Formosa Television, compared the differences between dubbing and subtitling. She posited that subtitles should help viewers comprehend the movie, instead of distracting them; they should clearly and fully convey the nuances of the source language in familiar Chinese colloquial expressions; they should omit modifiers, and should leave no trace of translation. Finally, the subtitles should be brief and concise.

\section{Integrated analysis: linguistic dimensions of subtitling}

Based on the four movies I have watched and analyzed, self-analysis of my own experience of subtitling over 300 English movies into Chinese, an analysis of existing literature, and interviews with two experienced subtitlers, I have highlighted the linguistic dimensions of subtitling. The results indicate that most of the techniques used in subtitling these movies can also be found in the existing literature. References are given to such sources. 
The linguistic dimensions of subtitling discussed in the rest of this paper consist of the followings sub-topics: Brevity and clarity, double-lined subtitling, omission, punctuation, structural discrepancy, and swearwords. Finally, a few words are expressed on the processes of subtitling.

\subsection{Brevity and clarity}

Subtitles should be as short and comprehensible as possible for three reasons: First, according to a study by Liu (1992), Chinese subtitles of English movies distract the viewers and decrease their comprehension ability because Chinese audiences get most of their information from reading the subtitles. Second, Liu pointed out that subtitles cause eye fatigue because watching English movies with subtitles forces the audience to focus on reading the subtitles. Third, subtitles that are too long take all the fun out of watching a film, such as a Discovery program. Brevity may be achieved by observing the following principles:

Use simple expressions, stock phrases, and collocations: Researchers generally agree that simple expressions that match the register and style of the source language should be used in subtitles in order to provide subtitles that take little effort to read and do not sound like translation. This is true for three reasons: First, using easy words, collocations, or phrases that are familiar to the viewers allows the audience to read the subtitles while at the same time concentrating on watching the pictures and listening to the music or conversation (Chin, 1997). Second, common phrases, stock phrases, or collocations are easier to comprehend than non-phrases (Gao \& Zhen, 1982). Third, Chiu, et al. (1999) showed that it is often more efficient to condense several long sentences into a short stock phrase.

In addition, brevity may be enhanced by the following strategies.

Condense: When the source language is redundant, too long, or too complicated, the target language subtitle should be condensed (using as few words as possible) to avoid confusing the audience (Huang, 2001). Thus, in most situations, the translator's job is to render the meaning as concisely as possible (Huang, 2001; Yeh, 1999).

Use Arabic numerals: Arabic numerals are easier to read, so they should be used instead of numbers in Chinese characters. However, when a large figure, e.g. "one trillion" is involved, it becomes easier to read if Chinese characters are used (Yi zhe shou ce, 2001; Chiu, et al.).

Restrict the length of the subtitles: No subtitle should exceed 14 Chinese characters (depending on the translation agency's policy).

Omit punctuation marks: Punctuation marks, such as the period and the comma at the end of a subtitle, should be omitted. In addition, punctuation marks should be used sparingly, because Chinese characters are ideographic and every word is either square or takes up a square space, so punctuation marks may ruin the aesthetics of the picture created by the Chinese characters.

Shift register: Common literary Chinese expressions should be used because they are dense in meaning, compared with spoken Chinese, and are able to reduce the length of subtitles. However, archaic literary Chinese expressions should be avoided because they may not be widely known. 


\subsection{Double-lined subtitles}

A subtitle may be split into a double-lined subtitle on the same screen when it exceeds the maximum length but cannot be condensed. The subtitle should be chunked appropriately so that each chunk is accurate, complete, and easily comprehensible at a glance (Yi zhe shou ce, 2001). It is essential to know how to create double-lined subtitles, when to use them, and when to avoid using them.

How should double-lined subtitles be created? The information in the source language should be chunked at a thought unit, at a conjunction, or between two clauses. Furthermore, each subtitle must be synchronized with the pictures, the source language subtitles, the narration, characters' utterances, and other relevant information in the source language. In terms of sentence structures, according to Lee (1988), follow Chinese syntactic rules when revising a subtitle involving more than two interrelated chunks, or inverted sentences, if the sentence can be expressed in one subtitle; otherwise, follow the English structure and make sure that the subtitles are fluent.

When should double-lined subtitles be used? According to Huang (2001), double-lined subtitles should be used on the following occasions: A subtitle that goes over the maximum word limit but cannot be shortened; two highly interrelated subtitles that must be connected together; two characters speaking in quick succession; the same character speaking with brief pauses.

What should be avoided? To avoid straining the eyes, avoid using double-lined subtitles or full-line subtitles in quick succession (Huang, 2001). In addition, doublelined subtitles should be avoided when the speaker or the narrator's delivery is very slow or when the picture is more important than the subtitles.

\subsection{Omission}

When the source language is dense, it is impossible to translate it in detail because doing so may result in subtitles that become too long, move too fast, and confuse the audience.

What should be omitted? Chiu, et al. (1999) showed that some information may be omitted if doing so enhances clarity and brevity. The following information may be omitted: the first and middle name after they have been mentioned once, the subtitles for a song unless it is important, fillers such as "you know" or "you see, redundant expressions, subjects and pronouns, the names of the director and other cast members unless they are important, minor details, and repeated phrases (by replacing them with three dots for ellipsis). For instance, in Chinese most nouns and pronouns can be omitted. Chin (1997) gave an example of a picture describing a chef cooking. The subtitle can omit the subject in "The chef is adding salt and pepper" and translate it into "Add salt and pepper" in Chinese.

What should be kept? Omission and abstracting that violate the synchronization with the speaker, the narrator, scenes, pictures, subtitles in the source language, and other relevant information should be avoided. 


\subsection{Punctuation}

Punctuation marks should be used sparingly not only for brevity but for aesthetics. The usage of two punctuation marks are discussed here: the period and quotation marks.

For brevity, the period at the end of a sentence is omitted but not the other punctuation marks. That is to say, a period should never be used in subtitles.

For explication, quotation marks (or parentheses) are used with a place name, the content of a letter, and words on the screen that are not said. In addition, they are also used for indicating that a foreign language (other than English) has been used.

For instance, in The Bridges of Madison County, "Mr. and Mrs. Richard Johnson" is subtitled with quotation marks. Another example is that when Francesca is reading a letter sent from Robert in the narration, within the subtitle, the content of the letter is in quotation marks, sentence by sentence.

However, when there are two sentences in a line, they should be separated with a comma or a space (by pressing the space bar twice). An exclamation mark or a question mark may be used at the end of a sentence as required (Huang, 2001).

\subsection{Structural discrepancy}

Structural discrepancy is the main difficulty in subtitling. In fact, subtitlers probably spend most of their time dealing with this issue. One strategy is to adapt the target language to fit the source language's context or situation. Another is to paraphrase, summarize, or abstract following the target language's writing conventions. No matter which strategy the subtitler uses, the following information may help solve the problem.

As a rule, the subtitle should follow the structure of the target language, not that of the source language. In addition, the translator should take into account the following situations, including the picture images, sound, and content involved (Chin, 1997). When the subtitle is long, involving more than three sentences, follow the Chinese usage convention. (Yi zhe shou ce, 2001). However, sometimes the sentences are not only long but also complex and very different from the source language. $Y i$ zhe shou ce gave the following advice on dealing with long sentences: First, revise the Chinese translation so that it becomes smooth and readable. Second, avoid direct translation that results in awkward Chinese sentences. Third, use double-lined subtitles for the Chinese to sound smooth.

\subsection{Swearwords}

Researchers generally agree that swearwords should be toned down. When and why?

When in doubt, tone down swearwords. The swear words should be toned down in the Chinese subtitles to make them sound less disgusting because nobody knows who is going to watch the movie, despite the content ratings. However, when the movie is geared to an adult audience, the subtitles should faithfully reflect the tone of the movie (Chen, 1996). Sometimes they are toned down because Chinese people with a status similar to those depicted in the American movies don't use as many swear words. 
Words referring to private parts should be omitted in the subtitles. In addition, in The Negotiator, when English swearwords that mention private parts are used, those words are omitted, and the swearwords are also toned down. And if sex-related words are used, they are toned down too. For instance, in the first scene of The Negotiator the hostage taker uses a lot of sex related swearwords. These swear words are either omitted or translated euphemistically.

The swearwords are toned down, or omitted, particularly when women are using them. For instance, when the wife (Linda) of the deceased policeman (Nathan) is curing another policeman (Danny Roman) who is suspected of killing her husband, she uses four-letter words, but in the Chinese subtitles these words are replaced with toned-down Chinese cursing words, Another instance is that whenever angry American policemen are speaking to each other in vehement tones, they tend to use a lot of swearwords; such words are also toned down or omitted in the Chinese subtitles. For example, the swearwords used by the Chicago policemen talking angrily to their superiors were either toned down or omitted in the Chinese subtitles.

Chinese subtitles have a greater variety of swearwords. Characters in American movies tend to use the same swearwords (specifically four-letter words) again and again. In such cases, Chinese subtitles need to use a greater variety of swearwords. For instance, in The Negotiator, the Chinese subtitles do not use as many swearwords (particularly four-letter words) as the source language does, nor does the TL use swearwords as often in real life. In English, the four-letter words frequently repeated in The Negotiator are translated into a wide variety of toned-down swearwords instead of using their Chinese four-letter word counterparts.

\subsection{Processes of subtitling}

Based on self reflections on my experience in subtitling and after consulting other subtitlers, we agree that subtitling is a process of information transfer from the source language (SL) to the target language (TL) and information reconstruction in the TL, following TL writing conventions. When the structures of the SL and the TL are similar, or the source language sentences are short, with frequent pauses, subtitling can be as smooth as consecutive interpretation. The difference is that the output in subtitling is written while that in consecutive interpretation is oral. However, when discrepancies in structures between the two languages arise, the subtitler has to backtrack and revise constantly. During the subtitling process, based on the pictures on the screen, the soundtrack of the characters, the narrators' utterances, transcriptions, or other information in the source language, the subtitler mentally breaks the source language into thought units, transfers them one by one into the target language in simple colloquial expressions appropriate in terms of register and style, and uses as many TL allocations, stock phrases, and idioms as possible. After that, the subtitler revises the target language to ensure that it complies with its syntactic structures, and that the expressions are simple, fluent, colloquial, and up-to-date, leaving no trace of translation. Finally, the subtitler follows the other aspects of the linguistic norms addressed in the previous sections of this paper. The parts of the entire process go on sometimes simultaneously, with frequent backtracking. An experienced subtitler can translate with less revision and backtracking. 


\section{Conclusion}

This paper identifies the roots of the problems in the poor quality of subtitling in Taiwan and mainly investigates the linguistic dimensions of subtitling. Translators are encouraged to consult the guidelines provided by their own translation agencies to get a good idea of how they are expected to subtitle because different agencies might expect slightly different styles. From the results of the study it becomes obvious that in order to enhance the quality of subtitling, some actions must be taken.

First, the translation community should pay attention to subtitling research and subtitler training. Second, the movie companies and translation agencies should pay subtitlers more to get the job done well by getting a colleague to proofread and edit the work. Finally, the government of Taiwan should impose copyright law more rigorously and eliminate the movie pirating businesses, which after all have created most of the poorly subtitled movies. Other researchers are encouraged to investigate the curriculum design and implementation of a subtitling course.

\section{NOTES}

* This paper is part of a research project funded by the ROC National Science Council under grant number NSC 91-2516-S-011-002. I would like to thank my colleagues Dr. Alicia Lloyd for reviewing this paper and Dr. C-M. Liang for translating the abstract into French. However, should there be any errors in this paper, I alone take full responsibility.

\section{REFERENCES}

\section{Primary sources}

Eastwood, C. (1997): The Bridges of Madison County, Warner Home Video.

Gray, F.G. (1998): The Negotiator, Warner Home Video.

Kathrens, G. (1993): Spirits of the Rainforest, Discovery Communications Inc.

Stone, O. (2001): Wall Street, Twentieth Century Fox Home Entertainment Inc.

\section{Secondary sources}

Chen, I. (1996): Lun zhong wen zh mu gan tan ci zhi fan yi. An unpublished MA thesis, Fu Jen Catholic University, Taiwan, ROC.

Chin, C. (1997): Ying thong zi mu fan yi de jing jian yuan ze. An unpublished MA thesis, Fu Jen Catholic University, Taiwan, ROC.

Chiu, C.T., K.C. Chen and M.Y. Chiang (Trans.) (1999): The features and analysis of subtitle translation. An unpublished report, National Yunlin University of Science and Technology, Taiwan, ROC.

Gao, S.R. and Z.M. Zhen (1982): Zhong guo yu wen de xin li xue yan jiu. Taipei: Wen He Chu Ban She.

Gong gong dien shi fa. (2001) <http://www.gio.gov.tw/info/radiotv/public/4.htm>.

Huang, P.S. (2001): Ri wen zh mu fan yi yu pei yin fan yi zhi bi jiao. An unpublished MA thesis, $\mathrm{Fu}$ Jen Catholic University, Taiwan, ROC.

LeE, C. (1988): Qian tan dian shi zh mu de zhi zhuo, Ying yu jiao xue, 13:1, pp. 23-26.

LiU, S. F. (1992): Dian shi zi mu dui shi jue han ju qing li jie du ying xiang zhi yan jiu. An unpublished MA thesis, National Chengkung University, Taiwan, ROC.

Lue, A. (1998): A Critique of Television News Translation. An unpublished MA thesis, Fu Jen Catholic University, Taiwan, ROC. 
Strauss, A., and J. Corbin (1990): Basics of Qualitative Research: Grounded Theory Procedures and Techniques, Newbury Park, CA: Sage Publications.

Yen, H. F. (1999): Cong gou tong li lun tan ying pian zi mu y u pei yin fan yi zhi yi tong. An unpublished MA. thesis, Fu Jen Catholic University, Taiwan, ROC.

Yi zhe shou ce. (2001): Taipei: Wei Lai Qi Ye You Xian Gong Si. 